\title{
Application of Nonlinear Dynamics in Studying Flashover Fire in a Small Open Kitchen
}

\author{
Wan Ki Chow*, Jing Liu \\ Research Centre for Fire Engineering, Department of Building Services Engineering, The Hong Kong Polytechnic \\ University, Hong Kong, China \\ Email: "beelize@polyu.edu.hk, "bewkchow@polyu.edu.hk
}

Received 29 March 2016; accepted 21 May 2016; published 24 May 2016

Copyright (C) 2016 by authors and Scientific Research Publishing Inc.

This work is licensed under the Creative Commons Attribution International License (CC BY). http://creativecommons.org/licenses/by/4.0/

(c) (i) Open Access

\begin{abstract}
Open kitchen designs are found in small units in tall residential buildings of Asian-Oceania regions for better space utilization. As many combustibles are stored in small residential units, fire originated in the open kitchen can grow and spread fast. Consequently, flashover can occur to give a big fire and result in severe casualties and property damage. Nonlinear dynamics can be applied to predict critical heat release rate to flashover in the unit with an open kitchen and will be illustrated in this paper. Based on a two-zone model, temperature of the hot smoke layer was taken as the system state variable. An evolution equation was developed with selective control parameters. Onsetting of flashover using a nonlinear dynamical system was demonstrated in the example residential units. Effects of the floor dimensions, the radiation feedback coefficient and thermal properties of wall material on the onset of flashover were then examined and analyzed. The developed nonlinear dynamical model for studying the onset of flashover gives a better understanding of the various control parameters.
\end{abstract}

\section{Keywords}

Bifurcation, Flashover, Nonlinear Dynamics, Open Kitchen, Small Residential Unit

\section{Introduction}

The fire safety of tall buildings associated with smoke movement and control, big fire due to wind action, firefighting accessibility and long evacuation time should be watched in densely populated areas in the Asia-

\footnotetext{
"Corresponding author.
} 
Oceania regions [1] [2]. In recent years, residential building fires were reported in skyscrapers [3] [4].

In Hong Kong, there are residential units in tall buildings with a floor area of less than $30 \mathrm{~m}^{2}$. Open kitchen design was employed to make this tiny unit more spacious. However, these open kitchen designs [5] in tall residential buildings give more fire hazards. As reported before [6], residential buildings stored many combustibles with fire load density up to $1400 \mathrm{MJm}^{-2}$. Kitchen is a hazardous area with naked flames cooking and usually enclosed with fire resisting construction. Cooking fire was the leading cause [7] for home fires and injuries. A small percentage fire of less than $5 \%$ escaping from kitchen accounted for a large proportion of the deaths and damages. Open kitchen fires in tall residential buildings should be watched.

A fire originating from the open kitchen spread beyond the cooking area can easily ignite combustibles stored in other parts of the unit. The fire can grow quickly to have flashover. The onset of flashover is usually considered as an indication of untenable condition, playing an extremely important role in disastrous fires [8]. Once flashover occurs, it will speed up the spread of the fire and even put the whole building at risk, causing a big post flashover fire. Therefore, it is very important to study flashover due to open kitchen fire in small residential units in tall buildings.

Efforts have been made to understand and predict flashover [9] [10]. Many factors were identified to have the transition of a growing fire to flashover. The commonly accepted criteria are that gas temperature below the ceiling reaches $500^{\circ} \mathrm{C}$ to $600^{\circ} \mathrm{C}$, or the radiation heat flux at floor level is $20 \mathrm{~kW} / \mathrm{m}^{2}$, or flames come out of the openings.

Flashover is characterized by a sharp increase in burning rate and gas temperature. Thermal instability is considered to be one of its mechanisms [9]. In a compartment fire, thermal radiation from the hot smoke layer and heated wall and ceiling surfaces increases the burning rate of the fuel to release more heat. Consequently, the smoke layer becomes hotter and then thermal feedback is also augmented. A positive feedback loop is formed. A relatively small and localized fuel-controlled fire suddenly can jump in a short moment to a big ventilation controlled fire involving all the exposed combustibles. This rapid jump is called flashover. The thermal instability nature of flashover suggests that it is a nonlinear dynamical process. Therefore, nonlinear dynamics theory can be applied to study flashover and started about three decades ago. Since then, different dynamical models appeared in the literature [11]-[20]. These models are typically based on simplified energy balance equations for a single compartment fire with the number of system state variables ranging from one to three. Such an approach [15] [16] was then updated and applied [18]-[20] to study flashover in an open kitchen fire as further illustrated in this paper. The nonlinear dynamics model developed will be used to predict the critical heat release rate necessary for the onset of flashover in a small unit with an open kitchen. The effects of geometry of the residential unit, wall materials and radiation feedback on the occurrence of flashover were examined.

\section{Nonlinear Dynamics Model for the Small Residential Unit}

The process of a fire in a small residential unit was considered as a dynamical system. Based on a two-layer zone model, the evolution equation was developed for the upper hot smoke layer. The upper smoke layer temperature was chosen as the state variable because it is important for predicting hazardous conditions. Change of the system state with time is of interest. The system behavior is dominated by control parameters, such as heat release rate, room configuration, opening geometry, and others. When one or more control parameters change, the system state responds accordingly. Normally, a small perturbation only causes a relatively slight variation in the system state. However, the system can experience violent change or bifurcations [15] [16] for qualitative changes in system state with its structure becoming qualitatively different at critical parameter values. Equilibrium state is a simple but important dynamical behavior of the system. The local stability of an equilibrium point or fixed point is also of great importance. When an equilibrium point loses its stability, bifurcation may occur. Eigenvalues of the constant Jacobian matrix at an equilibrium point can help to determine the local stability of it. The fixed point is stable if all eigenvalues are negative and unstable if at least one eigenvalue is positive. When eigenvalues become zero, bifurcation might take place. In this application on room fire, the system jumps from the current equilibrium state to a new remote one when bifurcation occurs. Such system jumps suggest flashover takes place.

An example residential unit adopted [18]-[20] as shown in Figure 1 has a length of $L$, width of $W$ and height of $H$. A single rectangular vent of width $W_{d}$ and height $H_{d}$ is located at the center of one wall. A fire source at the open kitchen is assigned at the room centered at the floor level. There will be no fire resisting wall enclosing 


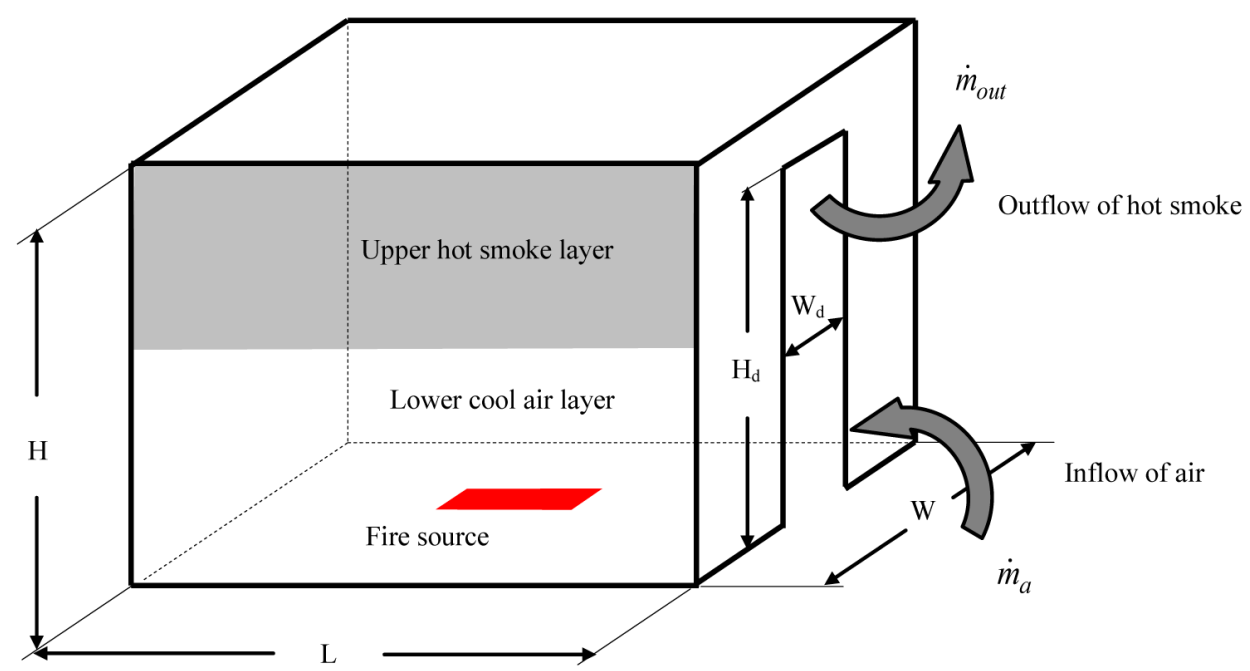

Figure 1. Diagram of the small residential unit.

the kitchen in that residential unit. Main assumptions made in the fire model are listed below:

- Density of the smoke layer is kept constant at ambient density $\rho_{0}$.

- The temperature of the lower air layer and its bounding surfaces are kept at the initial temperature $T_{0}$.

- Surface temperature of the fire source is assumed to be the ambient value $T_{0}$ and its emissivity is taken to be 1 .

- Before flashover, the fire is assumed to be quasi-steady and the height of the smoke layer interface is constant and kept at $0.5 \mathrm{H}$ [9].

- The height of the neutral plane coincides with the height of the smoke layer interface.

- In ventilation-controlled stage, the air entering into the residential unit is assumed to be completely consumed.

- The wall surface is assumed to be black body and the emissivity of the smoke layer is assumed to be 1 .

The evolution equation was developed based on the energy conservation for the upper hot smoke layer. It takes a similar form as described [11]-[16] in terms ofthe mass of the smoke layer $m$, the specific heat capacity at constant pressure $c_{p}$, the average temperature of the hot smoke layer $T$ at time $t$, net heat gain rate $G_{E}$ and net loss rate $L_{E}$ of the hot smoke layer.

$$
m \cdot c_{p} \cdot \frac{\mathrm{d} T}{\mathrm{~d} t}=G_{E}-L_{E} .
$$

The terms $G_{E}$ and $L_{E}$ are functions of smoke layer temperature. $G_{E}$ is determined by the fraction of the heat release rate of the fire $\dot{Q}$ that goes into the upper smoke layer. Part of the energy released by a fire is emitted by radiation and does not enter the smoke layer. $G_{E}$ can be written as:

$$
G_{E}=\left(1-\chi_{R}\right) \cdot \dot{Q} \text {. }
$$

For fire plumes resulted from common fuels, the radiant part $\chi_{R}$ typically accounts for $20 \%$ to $40 \%$ of the total energy released [10].

The heat release rate of a room fire can be calculated for fuel-controlled fire and ventilation-controlled fire. For a fuel-controlled fire, there is enough air for combustion and the heat release rate $\dot{Q}$ depends on the mass of combustible gas released and given by the free burning heat release rate of the fire $\dot{Q}_{0}$; the combustion efficiency $\chi$; the additional burning rate due to thermal feedback from the enclosure and hot smoke $\dot{m}_{f}$; and the heat of combustion of the fuel $H_{\text {com }}$.

$$
\dot{Q}=\dot{Q}_{0}+\chi \cdot \dot{m}_{f} \cdot H_{\text {com }} .
$$

For a ventilation-controlled fire, excess fuel is released and the heat release rate is dominated by the mass flow rate of air $\dot{m}_{a}$ into the compartment and the stoichiometric air to fuel mass ratio $r$. 


$$
\dot{Q}=\chi \cdot \frac{\dot{m}_{a}}{r} \cdot H_{\text {com }}
$$

Further, $\dot{m}_{f}$ can be determined by the net incident radiant heat on the fuel surface $\dot{R}_{i n}$ and the heat of evaporation or gasification of the fuel $H_{\text {vap }}$.

$$
\dot{m}_{f}=\frac{\dot{R}_{\text {in }}}{H_{\text {vap }}} .
$$

In a compartment fire, the hot smoke layer and heated boundary surfaces radiate heat back to the fuel surfaces, which accelerate the gasification rate of the fuel. This radiant feedback has been recognized as playing an important role in the onset of flashover [21]. $\dot{R}_{\text {in }}$ is calculated by a simplified equation in terms of the Stefan-Boltzmann constant $\sigma$, the radiant feedback coefficient $\mu$; and the ambient temperature $T_{0}$.

$$
\dot{R}_{\text {in }}=\mu \cdot \sigma \cdot\left(T^{4}-T_{0}^{4}\right) L \cdot W .
$$

In a ventilation-controlled fire, the gas temperature is most often very high and the smoke gas isroughly mixed evenly. The inflow of air through openings can be obtained [10] from the width $W_{d}$ and height $H_{d}$ of the opening:

$$
\dot{m}_{a}=0.5 \cdot W_{d} \cdot H_{d}^{1.5} .
$$

The energy lost from the hot smoke layer $L_{E}$ is composed of mass flow through the opening, convection and radiation heat loss to the solid boundary and radiation loss to the opening.

$$
L_{E}=\sigma\left(T^{4}-T_{0}^{4}\right)\left[L W+W_{d}\left(H_{d}-Z\right)\right]+A_{w} \sigma\left(T^{4}-T_{w}^{4}\right)+A_{w} h_{t}\left(T-T_{w}\right)+c_{p} \dot{m}_{\text {out }}(T-T)_{0}
$$

where $Z$ is the height of the smoke layer interface from the floor level; and $h_{t}$ is the convective heat transfer coefficient. $T_{w}, A_{w}$ are the surface temperature and surface area of the upper parts of the solid boundaries enclosing the hot smoke gas respectively. $A_{w}$ is given by:

$$
A_{w}=L W+\left(2 L+2 W-W_{d}\right)(H-Z)+\left(H-H_{d}\right) W_{d} .
$$

There are four items on the right hand side of Equation (8). The first item is the radiative heat loss from the smoke layer to the lower part of the compartment and vent. The second item and the third item are the radiative and convective heat loss to ceilings and the upper part of the walls, respectively. The forth item is the enthalpy flowing out through the vent.

For simplicity, surface temperature of the heated walls $T_{w}$ is approximated as a fraction of the smoke layer temperature [12]:

$$
T_{w}=U_{c}\left(T-T_{0}\right)+T_{0} .
$$

Note that $U_{c}$ is a wall temperature parameter ranging from 0 to 1 and depends on the thermal inertia of wall materials.

As demonstrated in Figure 1, hot smoke flows out through the upper part of the opening and fresh air enters from the lower part. The outflow rate $\dot{m}_{\text {out }}$ driven by buoyancy through the vent can be estimated [22] in terms of the flow coefficient $C_{d}$; the height of neutral plane from floor $Z_{N}$ where the pressure deference across the opening is zero; and the acceleration due to gravity $g$.

$$
\dot{m}_{\text {out }}=\frac{2}{3} C_{d} \cdot \rho_{0} \cdot W_{d} \cdot H_{d}^{\frac{3}{2}} \sqrt{2 \cdot g\left(1-\frac{Z_{N}}{H_{d}}\right) \frac{T_{0}}{T}\left(1-\frac{T_{0}}{T}\right)}\left(1-\frac{Z_{N}}{H_{d}}\right) .
$$

For simplicity, $Z_{N}$ was assumed to be coincided with $Z$, equation (11) can be rewritten as:

$$
\dot{m}_{\text {out }}=\frac{2}{3} C_{d} \cdot \rho_{0} \cdot W_{d} \cdot\left(H_{d}-Z\right)^{\frac{3}{2}} \sqrt{2 \cdot g \frac{T_{0}}{T}\left(1-\frac{T_{0}}{T}\right)} .
$$


According to the dynamical theory, equilibrium points of the dynamical system meet:

$$
\left.\frac{\mathrm{d} T}{\mathrm{~d} t}\right|_{T=T_{\text {equ }}}=0
$$

where $T_{\text {equ }}$ is the system state value at equilibrium points, its corresponding eigenvalues $\lambda$ can be obtained by:

$$
\lambda=\left.\frac{\partial}{\partial T} \frac{\mathrm{d} T}{\mathrm{~d} t}\right|_{T=T_{\text {equ }}} .
$$

If the value of $\lambda$ is equal to zero at certain equilibrium point, then flashover is considered to happen here.

The control parameters and constants are set values as listed in Table 1, unless otherwise specified. Some of the values are taken out from literature [23].

\section{Onsetting of Flashover}

Onsetting of flashover was further demonstrated [18] [19] by the nonlinear dynamical model for another two residential units with open kitchen. One was $6 \mathrm{~m}$ long, $5 \mathrm{~m}$ wide and $3 \mathrm{~m}$ high. The other was $5 \mathrm{~m}$ long, $5 \mathrm{~m}$ wide and $3 \mathrm{~m}$ high. Curves for energy gain rate $G_{E}$ and energy loss rate $L_{E}$ were plotted against the upper smoke layer temperature respectively as shown in Figure 2 and Figure 3. The relationship of the two curves is different in the two cases. When the floor is $5 \mathrm{~m}$ by $5 \mathrm{~m}$, it was very similar to the case when the floor is $6 \mathrm{~m}$ by $3.5 \mathrm{~m}$ which was discussed before [19].

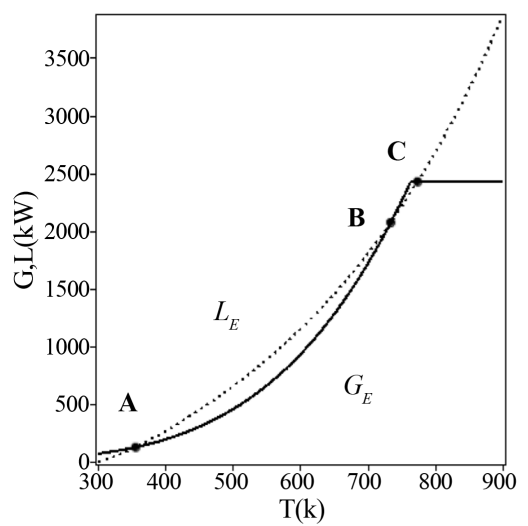

(a) $\dot{Q}_{0}=100 \mathrm{~kW}$

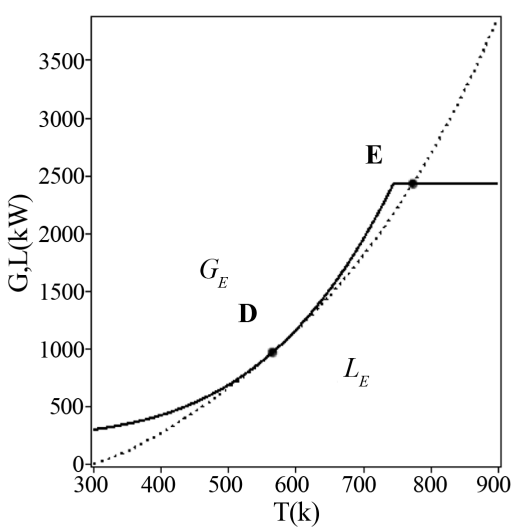

(b) $\dot{Q}_{0}=439 \mathrm{~kW}$

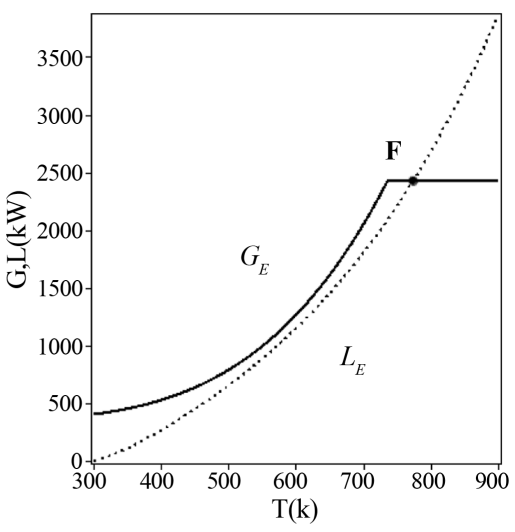

(c) $Q_{0}=600 \mathrm{~kW}$

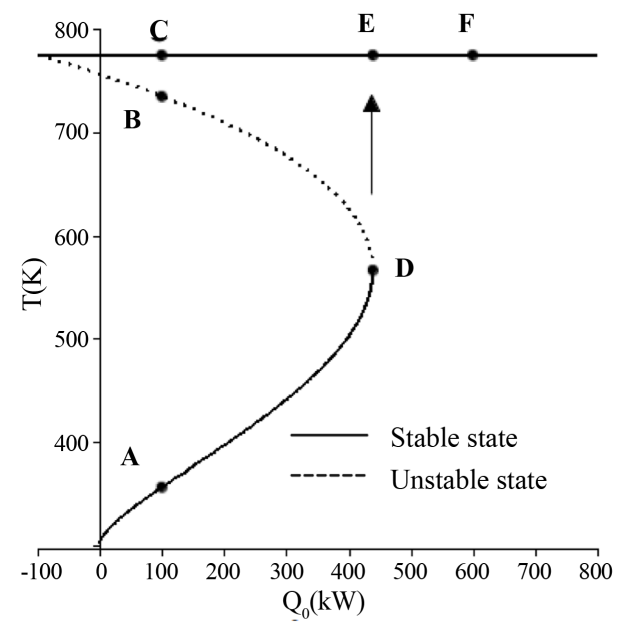

(d) Eigenvalues for equilibria

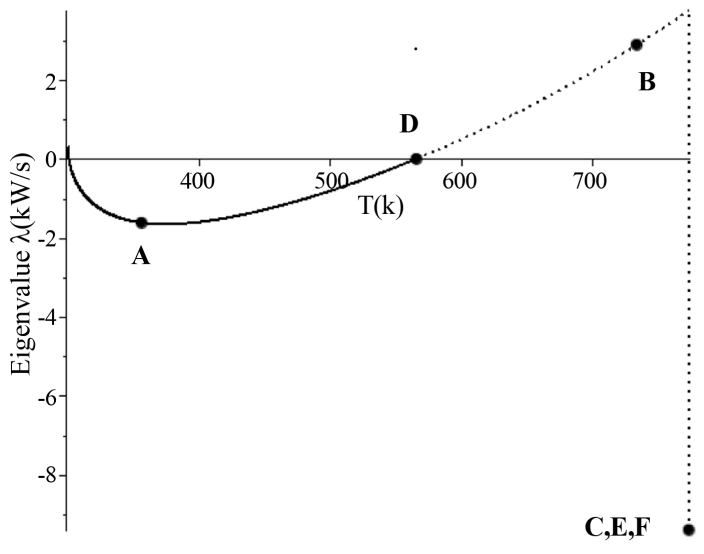

(e) Schematic of bifurcation

Figure 2. Demonstration of bifurcation for the unit of size $6 \mathrm{~m}$ by $5 \mathrm{~m}$ by $3 \mathrm{~m}$. 


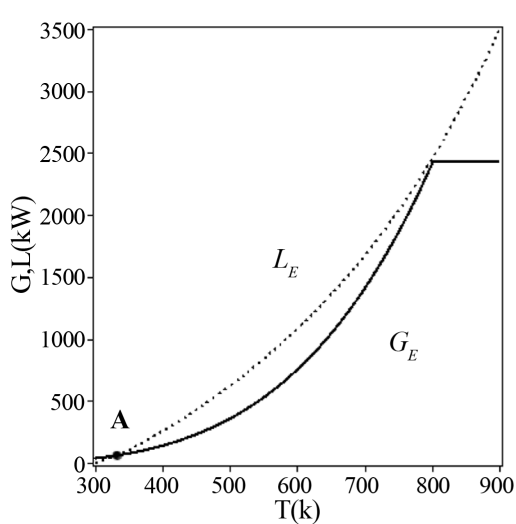

(a) $\dot{Q}_{0}=50 \mathrm{~kW}$

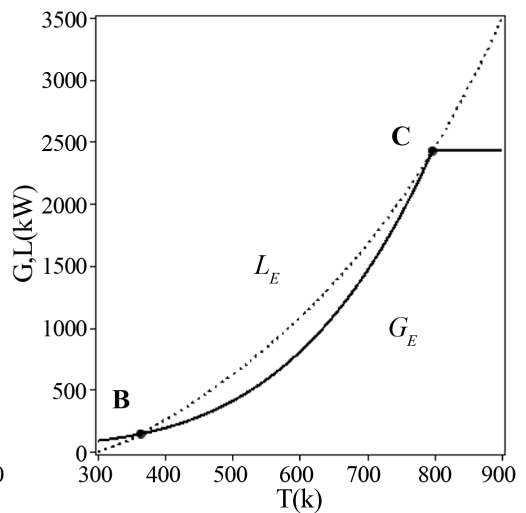

(b) $\dot{Q}_{0}=128 \mathrm{~kW}$

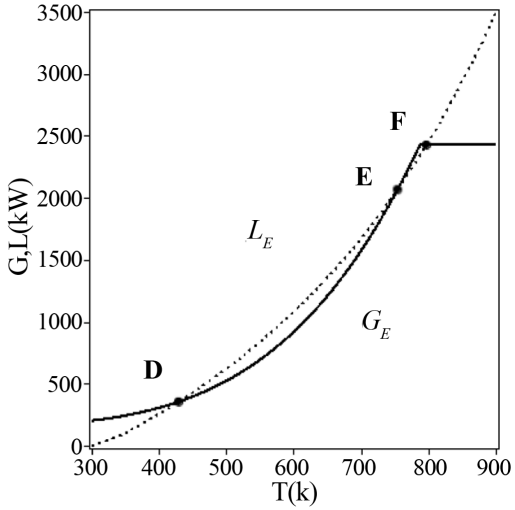

(C) $\dot{Q}_{0}=300 \mathrm{~kW}$

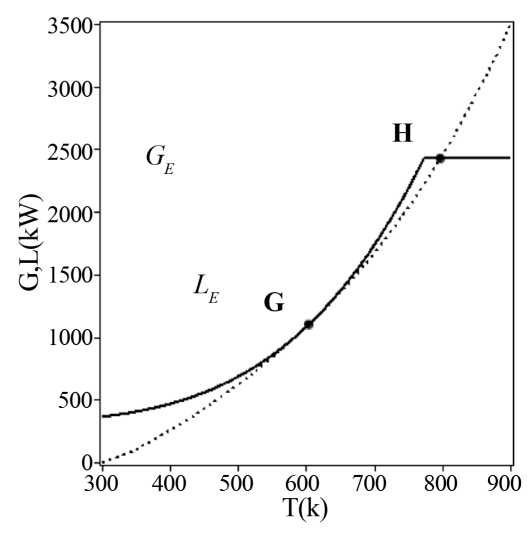

(d) $\dot{Q}_{0}=540 \mathrm{~kW}$

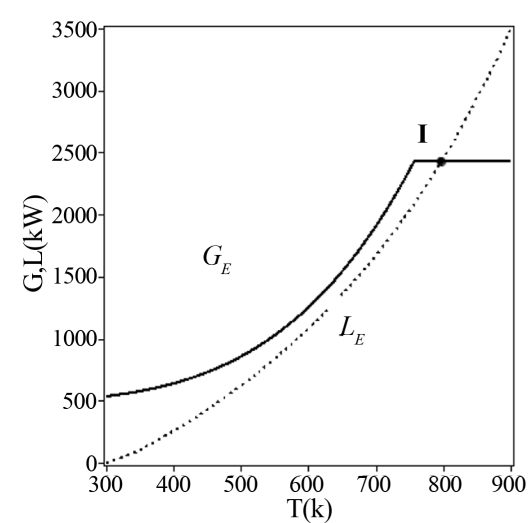

(e) $\dot{Q}_{0}=800 \mathrm{~kW}$

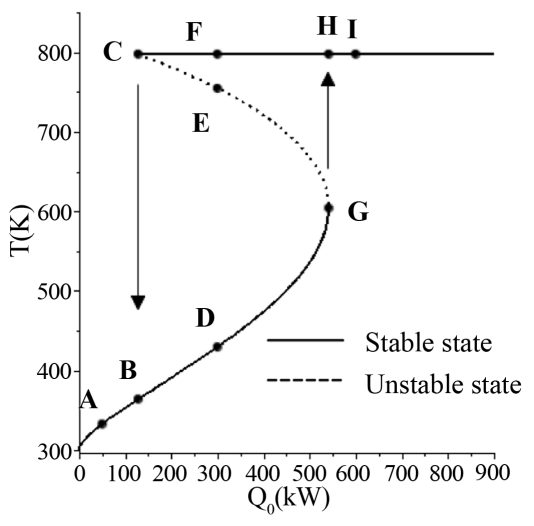

(f) Schematic of bifurcation

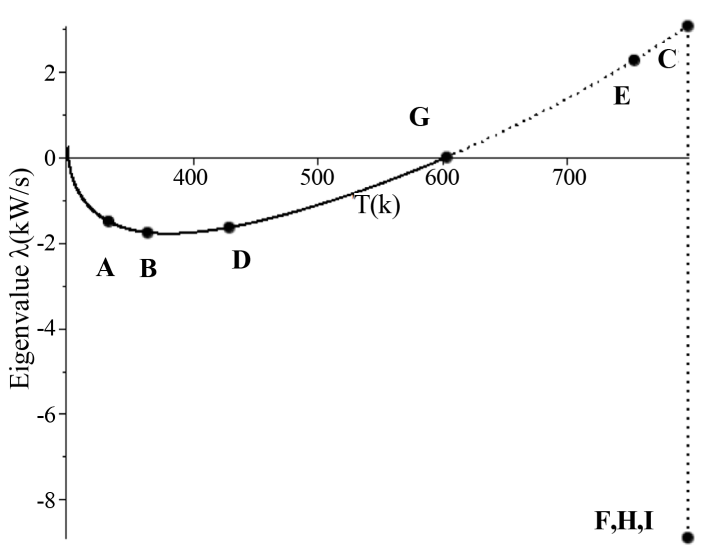

(g) Eigenvalues for equilibria

Figure 3. Demonstration of bifurcation for the unit of size $5 \mathrm{~m}$ by $5 \mathrm{~m}$ by $3 \mathrm{~m}$.

For the case with floor geometry of $6 \mathrm{~m}$ by $5 \mathrm{~m}$, as shown in Figure 2, when the value of parameter $\dot{Q}_{0}$ increases, the relative positions of the two curves also change. There are three, two or one intersections for the two curves. These intersections represent different equilibrium states of the fire system. From a temperature perturbation analysis, it is easy to find that equilibrium point $\mathrm{A}$ in Figure 2(a) is stable. When a fire progresses to point $A$ the temperature of the smoke layer will stabilize at a relatively low temperature. While the equilibrium state at points B is unstable. The more dangerous situation is point D in Figure 2(b) which is of great interest. If 
Table 1. Selected values for parameters.

\begin{tabular}{cccc}
\hline Parameters & Values & Parameters & Values \\
\hline$\sigma$ & $5.67 \times 10^{-8} \mathrm{~W} \cdot \mathrm{m}^{-2} \cdot \mathrm{K}^{-4}$ & $\mu$ & 0.15 \\
$c_{p}$ & $1003.2 \mathrm{~J} / \mathrm{kg} \cdot \mathrm{K}$ & $r$ & 30 \\
$C_{d}$ & 0.7 & $T_{0}$ & $300 \mathrm{~K}$ \\
$g$ & $9.81 \mathrm{~m} \cdot \mathrm{s}^{-2}$ & $U_{c}$ & 0.7 \\
$h_{c}$ & $7 \mathrm{~W} \cdot \mathrm{m}^{-2} \cdot \mathrm{K}^{-1} \cdot \mathrm{W} / \mathrm{m}^{2} \cdot \mathrm{K}$ & $W_{d}$ & $1 \mathrm{~m}$ \\
$H$ & $3 \mathrm{~m}$ & $Z$ & $1.5 \mathrm{~m}$ \\
$H_{\text {com }}$ & $4.2 \times 10^{7} \mathrm{~J} / \mathrm{kg}$ & $\chi$ & 1 \\
$H_{d}$ & $3 \mathrm{~m}$ & $\chi_{R}$ & $1 / 3$ \\
$H_{\text {vap }}$ & $1.008 \times 10^{6} \mathrm{~J} / \mathrm{kg}$ & $\rho_{0}$ & $1.18 \mathrm{~kg} \cdot \mathrm{m}^{-3}$ \\
\hline
\end{tabular}

there is a small increase in temperature at point $\mathrm{D}$, the fire will jump rapidly from an equilibrium state to a new stable state E, i.e. flashover occurs. When $\dot{Q}_{0}$ is larger than $439 \mathrm{~kW}$, the fire will continually grow to a ventilation-controlled state as shown in Figure 2(c) and there is no thermal instability.

Eigenvalues in Figure 2(d) can help to determine the stability of equilibrium points. As shown in Figure 2(e), the branch $\mathrm{AD}$ is stable because the corresponding eigenvalues in Figure 2(d) are negative. Vice versa, branch $\mathrm{DB}$ is unstable. The stable branch intersects the unstable branch at point $\mathrm{D}$ whose eigenvalue is zero. When a small fire starts on branch $\mathrm{AD}$, as the free burning heat release rate of the fire increases, the fire will eventually reach $\mathrm{D}$ and a fold catastrophe occurs. At point $\mathrm{D}$, the system state rapidly jumps from a fuel-controlled equilibrium point to a new remote ventilation-controlled equilibrium state denoted by point $\mathrm{E}$ with a sharp increase in temperature. Flashover occurs at this bifurcation point. The heat release rate is about $1444 \mathrm{~kW}$ and the smoke layer temperature is $556 \mathrm{~K}$ for bifurcation point $\mathrm{D}$. The new state $\mathrm{E}$ has a temperature of $774 \mathrm{~K}$.

\section{Effect of the Residential Unit Geometry}

To consider the effect of unit geometry on the onsetting of flashover, critical conditions for five units with different floor dimensions but same room ceiling height ( $3 \mathrm{~m}$ ) were evaluated. The five cases were labeled as C1 (6 m by $3.5 \mathrm{~m})$, C2 (7 m by $3 \mathrm{~m})$, C3 ( $5 \mathrm{~m}$ by $5 \mathrm{~m})$, C4 ( $6 \mathrm{~m}$ by $5 \mathrm{~m})$ and C5 (7.5 m by $4 \mathrm{~m})$ respectively.

In these cases, the radiation feedback coefficient is kept at a constant value of 0.15 , though they vary with the compartment geometry and the fire process. The values for critical temperature, critical heat release rate and equilibrium temperature after flashover discussed before [19] are presented in Table 2.

Three floor area values $21 \mathrm{~m}^{2}, 25 \mathrm{~m}^{2}$ and $30 \mathrm{~m}^{2}$ were investigated. For units with a larger floor area, the critical heat release rate for flashover is lower. In the fire model developed, the thermal radiation feedback is closely related with the smoke layer interface area, which is equal to the floor area. If the other conditions are the same, as the floor area increases, the fire base receives more energy feedback from the upper part of the compartment. But for a large compartment, it may take a longer time to reach a higher temperature.

C1 and C2, C4 and C5 are of the same floor area but different aspect ratio respectively, giving different internal surface areas. For residential units with the same floor area, when the internal surface area is small, the values of critical temperature and critical heat release rate are lower than those with a larger internal surface area. When the internal surface area of an apartment is small, less heat is conducted away from the enclosure boundary, allowing more energy to be stored in the unit. Therefore, a smaller heat release rate would onset flashover to give a higher compartment temperature.

\section{Effect of Radiation Feedback}

Radiation feedback from the smoke layer to the fire source is assumed to be the driving force to the onset of flashover in this study based on thermal instability. The heat feedback process is complicated and affected by the geometry of the enclosure, the concentration of the participating media such as carbon monoxide and soot, the thickness and temperature of the smoke layer and other factors. Heat radiated to the fuel is simplified in the 
Table 2. Critical flashover conditions for units with different geometry.

\begin{tabular}{cccccccc}
\hline Cases & $\begin{array}{c}\text { Floor dimensions } \\
(\mathrm{mm})\end{array}$ & $\begin{array}{c}\text { Solid surface area enclosing } \\
\text { hot smoke } A_{w}\left(\mathrm{~m}^{2}\right)\end{array}$ & $\begin{array}{c}\text { Critical temperature } \\
(\mathrm{K})\end{array}$ & $\begin{array}{c}\text { Free burning heat release } \\
\text { rate }\end{array} \dot{Q}_{0}(\mathrm{~kW})$ & $\begin{array}{c}\text { Critical heat release } \\
\text { rate } \dot{Q}(\mathrm{~kW})\end{array}$ & $\begin{array}{c}\text { New stable } \\
\text { Temperature }(\mathrm{K})\end{array}$ \\
\hline $\mathrm{C} 1$ & $6 \times 3.5$ & 48 & 647 & 656 & 1898 & 818 \\
$\mathrm{C} 2$ & $7 \times 3$ & 49.5 & 652 & 669 & 1953 & 814 \\
$\mathrm{C} 3$ & $5 \times 5$ & 53.5 & 604 & 542 & 1694 & 772 \\
$\mathrm{C} 4$ & $6 \times 5$ & 61.5 & 566 & 439 & 447 & 1444 & 774 \\
$\mathrm{C} 5$ & $7.5 \times 4$ & 63 & 569 & 447 & 1475 & 772 \\
\hline
\end{tabular}

present study using the radiation feedback coefficient $\mu$ in equation (6), which implicitly incorporates the effect from emissivity and view factor. Only radiation from the smoke layer is considered and radiation from hot surfaces is neglected.

Taking the residential unit in C4 as an example, effect of parameter $\mu$ on the onset of flashover was evaluated. The other parameters are kept the same as values in Table 1. Figure 4(a) shows the critical heat release rate and critical temperature for flashover under varying $\mu$, respectively. Critical conditions under different $\mu$ for a unit in C1 was reproduced [19] in Figure 4(b) for comparison.

As demonstrated in Figure 4(a), lower heat is radiated back to the fire source when the value of $\mu$ is low. Flashover does not occur. When the radiation feedback coefficient $\mu$ increases, the critical heat release rate for flashover drops quickly at first, then varies gradually. When $\mu$ is 0.1 , the critical heat release rate and critical temperature are about 5.3 MW and $880 \mathrm{~K}$ respectively. Under strong radiation feedback with $\mu$ of 0.2 , the minimum heat release rate required for onsetting flashover is only $0.84 \mathrm{MW}$ and the corresponding critical temperature is $478 \mathrm{~K}$. Therefore, flashover can occur earlier under strong radiation feedback to have fast fire growth rate.

\section{Effect of the Wall Materials}

Heat lost in a room fire through the wall depends on the material properties of the boundaries. Effect of wall properties on onsetting flashover was studied [20].

If the thermal inertia of the wall is large, the wall temperature parameter $U_{c}$ in Equation (10) is small and more heat is lost through the walls due to a larger temperature difference between the hot smoke and the solid boundary. If the thermal inertia is small enough, $U_{c}$ is nearly 1 and the wall has a good insulation performance.

Heat lost through the wall $Q_{L}$ can be roughly estimated [24] [25] by:

$$
Q_{L}=h_{c} \cdot A_{w} \cdot\left(T-T_{0}\right)
$$

where $h_{c}$ is an effective heat transfer coefficient.

For simplification, the heat transfer through the solid boundary is presumed to reach a steady state, and then the value of $h_{c}$ can be determined by:

$$
h_{c}=C_{1} \frac{k_{w}}{d_{w}}
$$

where value of $C_{1}$ is 0.4 for compartment fires [24]; $k_{w}$ is the thermal conductivity and $d_{w}$ is thickness of the wall.

Actually, walls of buildings are made of layered material, it was assumed in studying flashover [20] that the solid boundary consists of only one layer material with a thickness of $0.1 \mathrm{~m}$. Heat transferred to the upper surfaces by radiation and convection can be assumed to equal the heat conducted into the solid. Thus, by replacing the second and the third items on the right hand side of Equation (8) with Equation (15), critical flashover conditions for various wall materials can be assessed.

Typical values for thermal properties and the steady-state value of $h_{c}$ for timber, gypsum plaster and concrete used before [20] with the wall taken to be a more realistic value of $0.1 \mathrm{~m}$ are presented in Table 3. Critical heat release rate and temperature for onsetting flashover for C1 through C5 are also shown. It can be seen that flashover can take place more easily in a unit enclosed with timber which has good insulation properties. 


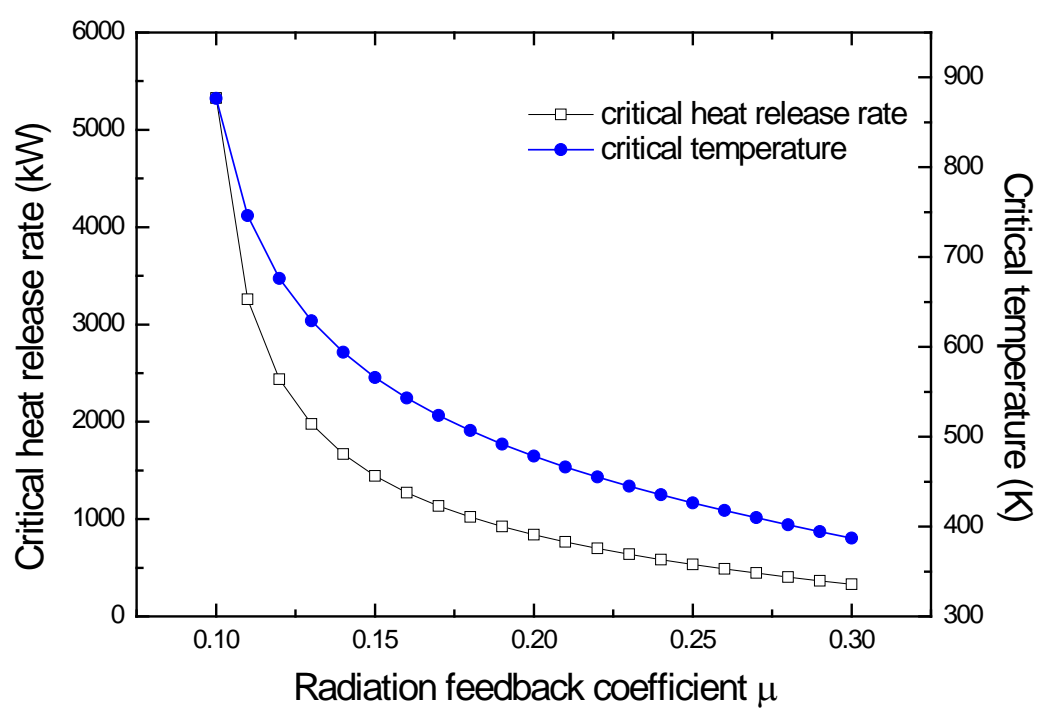

(a) Unit of $6 \mathrm{~m}$ by $5 \mathrm{~m}$

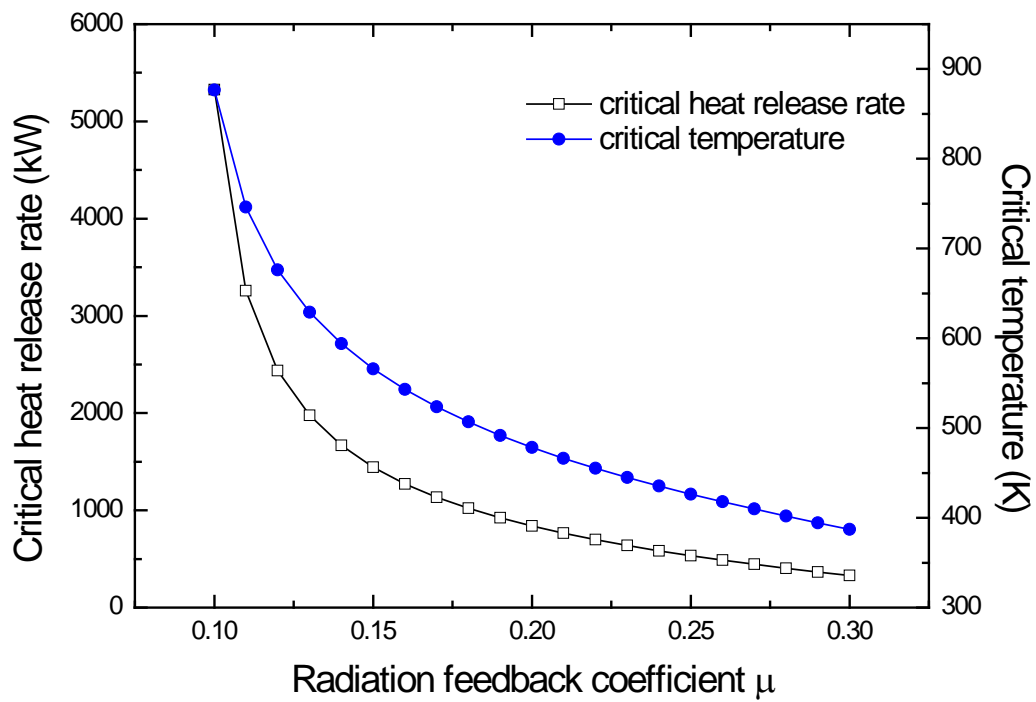

(b) Unit of $6 \mathrm{~m}$ by $3.5 \mathrm{~m}$, from Liu and Chow (2016)

Figure 4. Critical flashover conditions under varying radiation feedback coefficient $\mu$.

\section{Conclusions}

Fire hazards associated with open kitchen in small residential units of tall buildings storing large amount of combustibles should be watched. A nonlinear dynamic model [15] [16] was employed and upgraded to quantitatively investigate the dangerous phenomenon of flashover in an open kitchen fire. Critical heat release rate and temperature for onsetting flashover were predicted under various unit floor dimensions, radiation feedback and wall materials.

It is observed that the solid boundary surface area or the floor aspect ratio will change the critical heat release rate and temperature for onsetting flashover, even for the same unit floor area. Consequently, architects can change the geometry of the residential unit with an open kitchen to give favorable conditions to mitigate the occurrence of flashover. The thermal properties of wall material also have effect on the critical conditions for flashover. Fire hazards of units with an open kitchen located in buildings enclosed with material of small thermal inertia should be given more caution.

Flashover in an open kitchen fire can be demonstrated by the model developed [15] [16] [18]-[20]. Although the state of the system depends on the values selected for the control parameters, such simplification and 
Table 3. Thermal properties of common wall materials of $0.1 \mathrm{~m}$ thick and critical conditions for flashover from Liu and Chow (2016).

\begin{tabular}{|c|c|c|c|c|}
\hline \multicolumn{2}{|c|}{ Materials } & Timber & Gypsum plaster & Concrete \\
\hline \multicolumn{2}{|c|}{ Thermal conductivity $k_{w} / \mathrm{W} \cdot \mathrm{m}^{-1} \cdot \mathrm{K}^{-1}$} & 0.12 & 0.8 & 1.6 \\
\hline \multicolumn{2}{|c|}{ Density $\rho_{w} / \mathrm{kg} \cdot \mathrm{m}^{-3}$} & 540 & 1700 & 2400 \\
\hline \multicolumn{2}{|c|}{ Specific heat capacity $c_{w} / J \cdot \mathrm{kg}^{-1} \cdot \mathrm{K}^{-1}$} & 2500 & 840 & 750 \\
\hline \multicolumn{2}{|c|}{ Steady state effective heat transfer coefficient $h_{c} / \mathrm{W} \cdot \mathrm{m}^{-2} \cdot \mathrm{K}^{-1}$} & 0.48 & 3.2 & 6.4 \\
\hline \multirow{4}{*}{$\begin{array}{l}\text { Critical heat release } \\
\text { rate } Q / \mathrm{kW}\end{array}$} & $\mathrm{C} 1$ & 978 & 1070 & 1177 \\
\hline & $\mathrm{C} 2$ & 978 & 1073 & 1186 \\
\hline & C3 & 868 & 964 & 1077 \\
\hline & $\mathrm{C} 4$ & 755 & 855 & 977 \\
\hline \multirow{6}{*}{$\begin{array}{c}\text { Critical temperature } \\
T / \mathrm{K}\end{array}$} & C5 & 756 & 855 & 983 \\
\hline & $\mathrm{C} 1$ & 544 & 552 & 562 \\
\hline & $\mathrm{C} 2$ & 544 & 553 & 563 \\
\hline & C3 & 516 & 525 & 535 \\
\hline & C4 & 488 & 498 & 509 \\
\hline & C5 & 488 & 498 & 510 \\
\hline
\end{tabular}

assumptions made on the complicated heat transfer process can be taken as a starting point for future development.

\section{Acknowledgements}

The work described in this paper is supported by a grant from the Research Grants Council of the Hong Kong Special Administrative Region, China for the project "Aspects of Open Kitchen Fires in Tall Building and Protection Alternatives” with account number B-Q27R.

\section{References}

[1] Chow, W.K. (2016) A Discussion on Tall Building Fire Safety in the Asia-Oceania Regions. In: Harada, K., Matsuyama, K., Himoto, K., Nakamura, Y. and Wakatsuki, K., Eds., Fire Science and Technology 2015: The Proceedings of 10th Asia-Oceania Symposium on Fire Science and Technology, Chap. 6, Springer, Singapore.

[2] Chow, W.K. (2015) Performance-Based Approach to Determining Fire Safety Provisions for Buildings in the AsiaOceania Regions. Building and Environment, 91, 127-137.

[3] China Daily (2010) 53 Killed in Shanghai as Fire Engulfs High-Rise. http://www.chinadaily.com.cn/china/2010-11/16/content 11553098.htm

[4] BBC News (2015) Fire in 336 m Dubai Residential Skyscraper. http://www.bbc.com/news/world-middle-east-31563894

[5] Chow, W.K. (2011) Fire Safety Concern on Open Kitchen in Small Residential Units of Tall Buildings. International Journal on Engineering Performance-Based Fire Codes, 10, 58-62. http://www.bse.polyu.edu.hk/researchCentre/Fire_Engineering/summary_of_output/journal/IJEPBFC/V10/P58-62.pdf

[6] Arup Hong Kong (2010) Research in East Asia. Arup Research Brochure, 19 p.

[7] Ahrens, M. (2013) Home Structure Fires. National Fire Protection Association, Quincy, MA, USA, 127 p.

[8] Rasbash, D.J. (1991) Major Fire Disasters Involving Flashover. Fire Safety Journal, 17, 85-93. http://dx.doi.org/10.1016/0379-7112(91)90030-3

[9] Thomas, P.H., Bullen, M.L., Quintiere, J.G. and McCaffrey, B.J. (1980) Flashover and Instabilities in Fire Behavior. Combustion and Flame, 38, 159-171. http://dx.doi.org/10.1016/0010-2180(80)90048-6

[10] Karlsson, B. and Quintiere, J.G. (2000) Enclosure Fire Dynamics. CRC Press, Boca Raton, Florida.

[11] Beard, A., Drysdale, D., Holborn, P. and Bishop, S. (1992) A Non-Linear Model of Flashover. Fire Science and Tech- 
nology, 12, 11-27. http://dx.doi.org/10.3210/fst.12.2_11

[12] Bishop, S.R., Holborn, P.G., Beard, A.N. and Drysdale, D.D. (1993) Nonlinear Dynamics of Flashover in Compartment Fires. Fire Safety Journal, 21, 11-45. http://dx.doi.org/10.1016/0379-7112(93)90003-9

[13] Beard, A., Drysdale, D., Holborn, P. and Bishop, S. (1994) A Model of Instability and Flashover. Journal of Applied Fire Science, 4, 3-16. http://dx.doi.org/10.2190/YEVD-CGCD-8MN0-BAYY

[14] Graham, T.L., Makhviladze, G.M. and Roberts, J.P. (1995) On the Theory of Flashover Development. Fire Safety Journal, 25, 229-259. http://dx.doi.org/10.1016/0379-7112(95)00049-6

[15] Liang, F.M., Chow, W.K. and Liu, S.D. (2002) Preliminary Studies on Flashover Mechanism in Compartment Fires. Journal of Fire Sciences, 20, 87-112. http://dx.doi.org/10.1177/0734904102020002746

[16] Liang, F.M., Liu, S.D. and Chow, W.K. (2013) Study on Flashover in an Open Kitchen Fire by Nonlinear Dynamics. Journal of Applied Fire Sciences, 23, 157-178. http://dx.doi.org/10.2190/AF.23.2.d

[17] Novozhilov, V. (2010) Nonlinear Dynamical Model of Compartment Fire Flashover. Journal of Engineering Mathematics, 67, 387-400. http://dx.doi.org/10.1007/s10665-009-9333-8

[18] Liu, J. and Chow, W.K. (2014) Study on Flashover in Small Residential Units with an Open Kitchen by Nonlinear Dynamics. Proceedings of the Tenth International Conference on Heat Transfer, Fluid Mechanics and Thermodynamics, Orlando, Florida, USA, 14-16 July 2014, 2238-2243.

[19] Liu, J. and Chow, W.K. (2016) Flashover Fires in Small Residential Units with an Open Kitchen. In: Memari, A.M. and Lowe, S.K., Eds., Proceedings of the 3rd Residential Building Design and Construction Conference, The Pennsylvania Housing Research Center, The Pennsylvania State University, USA, 395-409.

[20] Chow, W.K. and Liu, J. (2015) Fire Hazards of Façade Materials for Energy Conservation under Flashover. Energy Procedia, 78, 3483-3488. http://dx.doi.org/10.1016/j.egypro.2016.02.001

[21] Yuen, W.W. and Chow, W.K. (2004) The Role of Thermal Radiation on the Initiation of Flashover in a Compartment Fire. International Journal of Heat and Mass Transfer, 47, 4265-4276. http://dx.doi.org/10.1016/j.ijheatmasstransfer.2004.05.017

[22] Rockett, J.A. (1976) Fire Induced Gas Flow in an Enclosure. Combustion Science and Technology, 12, 165-175. http://dx.doi.org/10.1080/00102207608946717

[23] Quintiere, J.G., McCaffrey, B.J. and Braven, K.D. (1979) Experimental and Theoretical Analysis of Quasi-steady Small-Scale Enclosure Fires. Symposium (International) on Combustion, 17, 1125-1137.

[24] Deal, S. and Beyler, C. (1990) Correlating Preflashover Room Fire Temperature. Journal of Fire Protection Engineering, 2, 33-48. http://dx.doi.org/10.1177/104239159000200201

[25] Chow, W.K. (2001) Flashover for Bus Fires from Empirical Equations. Journal of Fire Sciences, 19, 81-93. http://dx.doi.org/10.1106/1Q30-NLP1-V354-4LY2 